\title{
Novas Formas para Velhos Fármacos
}

VÂNIA ANDRÉ*

\begin{abstract}
0
desenvolvimento de novas formas de princípios farmacologicamente ativos (PFA) é um tema que tem recebido particular atenção nos últimos anos com vista a melhorar as suas propriedades físico-químicas e o seu desempenho terapêutico. Foram desenvolvidas várias formas cristalinas ao longo deste projeto com base nos princípios de engenharia de cristais, que racionaliza a sua formação e o seu modo de agregação supramolecular. São exemplos: polimorfos, solvatos, co-cristais, sais moleculares e sais obtidos em estudos com gabapentina, gabapentina-lactama, ácido 4-aminosalicílico, paracetamol e erbumina de perindopril. Testes de solubilidade realizados com co-cristais de gabapentina e gabapentina-lactama revelaram que estes apresentam melhores características que o PFA inicial. Um novo hidrato de erbumina de perindopril demonstrou ser mais estável face ao produto atualmente comercializado. A coordenação de PFA a metais é uma outra forma de melhorar o seu desempenho e desenvolver materiais bio-inspirados. Exemplos deste tipo de complexos são os compostos de coordenação de piracetama e ácido 4-aminosalicílico a níquel e prata, respetivamente. Além destes resultados, foi ainda conseguida a síntese da metalodroga bismuto de salicilato através de moagem assistida por solvente e iões. Este método de "química verde" permitiu a síntese rápida, seletiva e eficiente de três formas de salicilato de bismuto, com diferentes rácios bismuto:ácido salicílico. Obteve-se neste estudo a primeira estrutura cristalina de salicilato de bismuto sem ligandos auxiliares.
\end{abstract}

\section{INTRODUÇÃO}

A procura de novas formas cristalinas é um dos tópicos atuais mais desafiantes da química do estado sólido, com importante impacto nas características físico-químicas, desempenho, produção, marketing e proteção da propriedade intelectual de materiais moleculares em várias áreas cientificas, com especial ênfase no desenvolvimento de princípios farmacologicamente ativos (PFA) [1-4]. Cada fármaco atualmente lançado no mercado resulta de 10-15 anos de trabalho intensivo e sustentado, que transforma uma simples molécula num fármaco pronto a ser consumido. Assim, é imperativo um estudo rigoroso e eficiente dos fármacos atualmente comercializados, com o objetivo de otimizar as suas propriedades (estabilidade, solubilidade e biodisponibilidade).

A combinação dos fundamentos de engenharia de cristais e química supramolecular [1-5] permite o design e a síntese de novas formas cristalinas de PFA, mantendo as propriedades farmacológicas originais e reduzindo drasticamente o tempo de introdu-

\footnotetext{
Centro de Química Estrutural, DEQ, Instituto Superior Técnico, UTL, Av. Rovisco Pais, 1049-001 Lisboa E-mail: vaniandre@ist.utl.pt
}

ção no mercado. A influência destas novas formas nas propriedades físico-químicas e desempenho de fármacos é ampla e diversificada, revelando-se nas características do estado sólido, tais como densidade, morfologia, cor e pontos de fusão. Não menos importante é a capacidade destas novas formas de alterarem a estabilidade à temperatura, humidade, $\mathrm{pH}$ e tempo, a solubilidade (equilíbrio de solubilidade e velocidade de dissolução) e a biodisponibilidade [6-9]. Problemas de formulação relacionados com fluidez, miscibilidade, granulação, encapsulamentos ou compactação, podem igualmente ser ultrapassados com o recurso a estes novos compostos [10,11]. No entanto, como já foi referido, a atividade intrínseca do PFAé mantida, uma vez que a sua identidade não foi alterada.

A engenharia de cristais, o design racional de sólidos moleculares funcionais, consiste na combinação de três etapas que definem "o quê", "como" e "porquê": 1) estudo das interações intermoleculares; 2) uso dessas interações na síntese de compostos através do desenvolvimento de estratégias para a construção de uma determinada arquitetura cristalina; 3) caracterização estrutural e sua correlação com as propriedades dos materiais para otimizar características específicas
[4, 12]. A química supramolecular, "a química para além da molécula", como foi definida por Jean-Marie Lehn, é a química da formação de agregados moleculares com base em interações não-covalentes [13]. A conjugação destes princípios, associada ao conhecimento das ligações por pontes de hidrogénio, sintões ${ }^{1}$ e grafos ${ }^{2}$, conduz à síntese racional de polimorfos, co-cristais, solvatos, sais moleculares e outros sais, entre outras formas $[1,5]$.

$\mathrm{Na}$ indústria farmacêutica tem sido dada uma ênfase especial aos co-cristais. Vários estudos têm demonstrado que esta é a forma cristalina por excelência para otimizar as propriedades de solubilidade e dissolução dos PFA em função do pH, mesmo com compostos não ionizáveis [18].

Foram utilizados métodos tradicionais de síntese e recristalização, mas mais interessante foi o recurso bem sucedido a técnicas verdes de mecanoquímica (moagem, moagem assistida por solvente e moagem assistida por solvente e iões) [19-21].

DESIGN E SÍNTESE DE NOVAS FORMAS CRISTALINAS

A procura com sucesso de novas formas cristalinas com o objetivo de 
melhorar propriedades específicas é baseada numa forte componente de análise de base de dados cristalográficos (Cambridge Structural Database [22]) para um design e planeamento eficazes.

Os ensaios de cristalização e co-cristalização são efetuados através da escolha criteriosa de métodos sintéticos e de condições de cristalização, que incluem várias técnicas de solução e mecanoquímica. A caracterização e avaliação das propriedades das novas formas são efetuadas com recurso a várias técnicas, desde difração de raios- $X$, usada na caracterização estrutural, a cromatografia líquida de alta pressão (HPLC), usada nos estudos de solubilidade e dissolução. Um sumário das fases envolvidas nestes estudos é apresentado na Figura 1.

Polimorfos, CO-CRISTAIS E OUTRAS FORMAS MULTICOMPONENTES NA MELHORIA DE PROPRIEDADES DE PFA

O principal objetivo deste trabalho foi, não simplesmente "fazer cristais com um objetivo", mas sim "definir novos objetivos para fazer cristais", tendo sido escolhidos PFA que, embora comercializados, apresentam problemas de formulação, processo ou desempenho.

Na Figura 2 apresentam-se os princípios farmacologicamente ativos utilizados em rastreios polimórficos, estudos de formas multicomponentes e coordenação a metais cujos resultados são aqui discutidos.

A gabapentina, um anticonvulsivo usado no tratamento da epilepsia, e a gabapentina-lactama, um pró-fármaco derivado da gabapentina com potenciais efeitos neurolépticos, apresentam elevada solubilidade e, embora a necessidade de diminuir a solubilidade seja pouco frequente, é por vezes necessária para aumentar a eficácia do fármaco. Em ambos os casos, após rastreios polimórficos e pesquisa de formas multicomponentes com ácidos carboxílicos, foram sintetizados, além de polimorfos [23] e um éster derivado da gabapentina [24], co-cristais com uma solubilidade mais adequada. Além desta melhoria na solubilidade (Figura 3 (a)), as no-

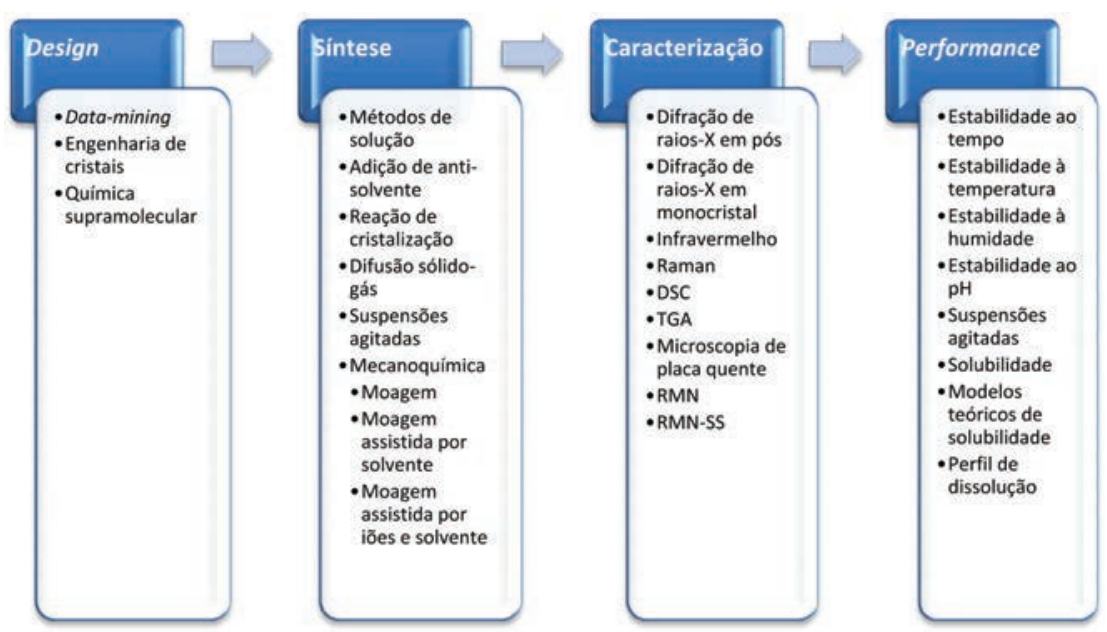

Figura 1 - Fases envolvidas no desenvolvimento de novas formas cristalinas

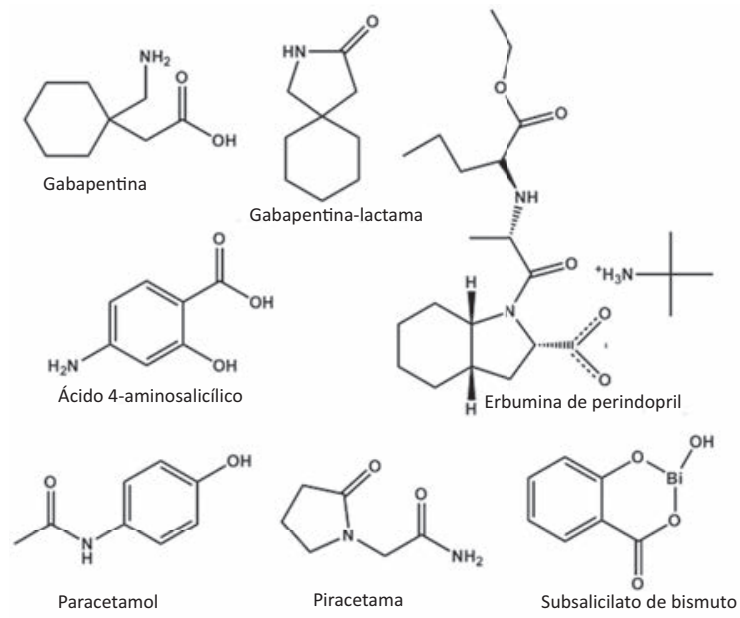

Figura 2 - Princípios farmacologicamente ativos utilizados em rastreios polimórficos, ensaios de formas multicomponentes e coordenação a metais
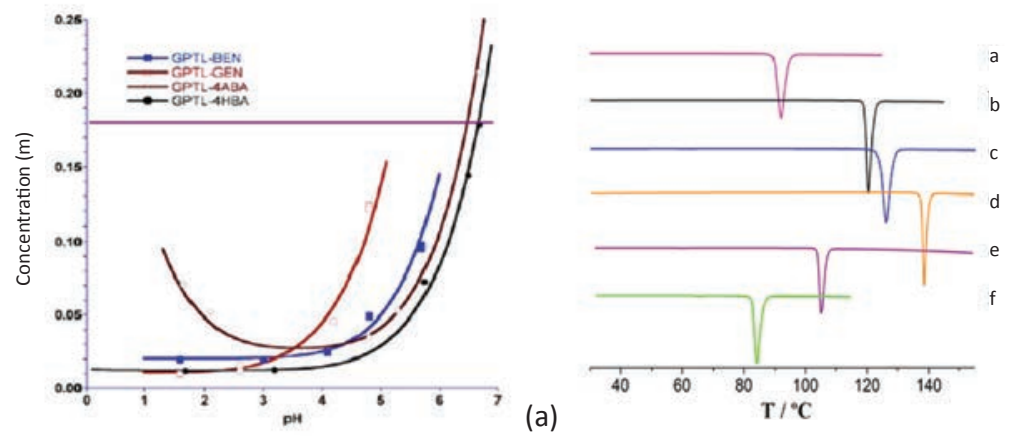

(b)

Figura 3 - (a) Dados de solubilidade e (b) termogramas para gabapentina-lactama (GPTL) e respectivos co-cristais com os ácidos 4-aminobenzóico (4ABA), gentísico (GEN), 4-hidroxibenzóico (4HBA), fumárico (FA) e benzóico (BEN)

vas formas são estáveis à temperatura (Figura 3 (b)), à humidade e na gama de pHs com relevância biológica $[23,25,26]$.

Estes exemplos comprovam a vantagem dos co-cristais na obtenção das solubilidades desejadas, mesmo com compostos não-ionizáveis, como a gabapentina-lactama. Estes estudos permitiram ainda o desenvolvimento de modelos matemáticos de solubilidade, que estão de acordo com os dados experimentais apresentados na Figura 3 (a) [26].

O ácido 4-aminosalicílico, um antibiótico usado no tratamento da tuberculose, apresenta limitações de biodisponibilidade. Estudos exploratórios resultaram na síntese de doze novas formas, entre solvatos, sais molecu- 
lares e co-cristais com heterociclos, que permitiram uma racionalização do comportamento deste PFA através da identificação das pontes de hidrogénio e sintões mais favoráveis, que estão a ser usados em estudos mais aprofundados (Figura 4). Foram estabelecidas várias correlações entre a estrutura e a estabilidade das novas formas [27, 28].

A erbumina de perindopril, fármaco usado no combate à hipertensão, é instável à temperatura, o que inviabiliza a sua comercialização em algumas zonas do planeta. O rastreio polimórfico permitiu a determinação das primeiras estruturas deste PFA e conduziu à síntese de um novo hidrato, mais estável à temperatura e à humidade, apresentando um perfil de dissolução semelhante ao do composto atualmente comercializado, mesmo quando misturado com excipientes (Figura 5) $[29,30]$.

A forma polimórfica I do paracetamol, um analgésico usado em larga escala, é a atualmente comercializada e é a mais estável, mas apresenta problemas no processo de compactação. A forma II é conhecida por ser mais apropriada para esta fase processual, mas é menos estável. Têm sido desenvolvidos vários esforços para tentar encontrar co-cristais que apresentem as características de compressibilidade da forma II e de estabilidade da forma I. Tendo em conta este objetivo, foram efetuados vários ensaios de co-cristalização dos quais se obtiveram três novos co-cristais. Pela análise dos arranjos supramoleculares destas formas, as propriedades de compactação aparentam ser mais favoráveis do que na forma comercializada, estando a ser efetuados estudos no sentido de confirmar esta hipótese.

A Tabela 1 sumariza os resultados obtidos através de estudos de novas formas cristalinas multicomponentes para os princípios farmacologicamente ativos discutidos.

CoORdenaçÃo de PFA a METAIS NA BUSCA DE SIMBIOSE DE EFEITOS

Uma outra forma de melhorar as propriedades de um PFA é através da sua coordenação a metais, numa ten-
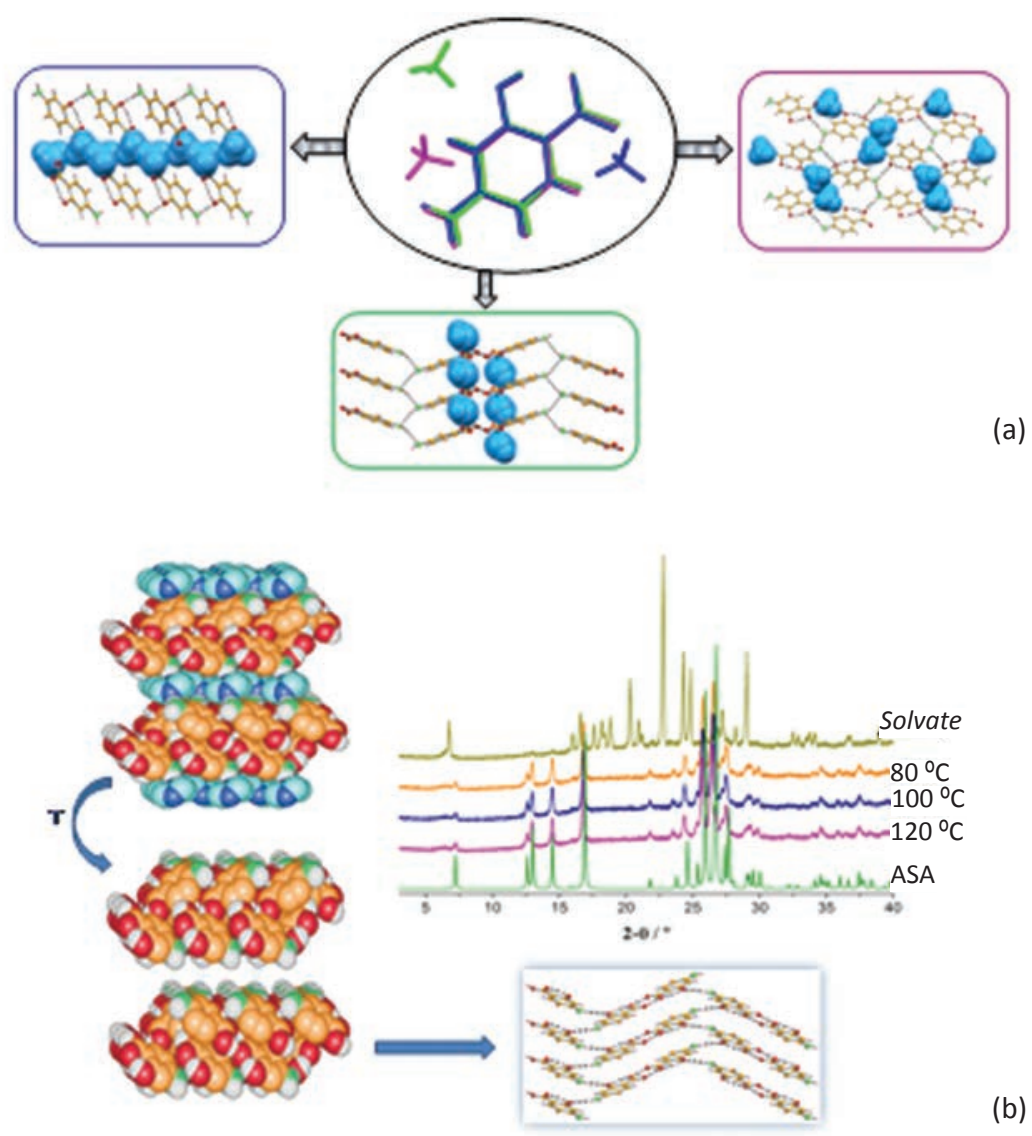

(b)

Figura 4 - Ácido 4-aminosalicílico (ASA): (a) empacotamentos cristalinos dos sais polimórficos de amónia (retirado de Vânia André et al. Cryst. Growth Des. 2012, 12, 3082-3090, com permissão. Copyright 2012 American Chemical Society); (b) a estrutura do solvato com dioxano permite interpretar a sua estabilidade térmica, através da saída dos "canais" de dioxano com a obtenção final do ASA, como comprovado por difração de raios-X em pós (adaptado de Vânia André et al. Cryst. Growth Des. 2009, 11, 5108-5111, com permissão. Copyright 2009 American Chemical Society)
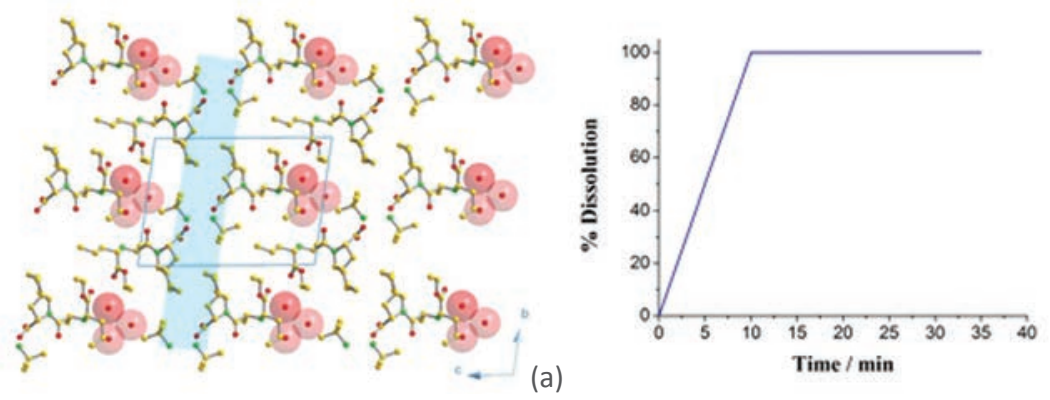

Figura 5 - (a) Empacotamento cristalino do novo hidrato de erbumina de perindopril; azul: dupla camada sustentada por pontes de hidrogénio; rosa: moléculas de água; (b) perfil de dissolução de nova forma hidratada com excipientes (adaptado de Vânia André et al. Cryst. Growth Des. 2011, 11, 3703-3706, com permissão. Copyright 2011 American Chemical Society)

tativa de alterar as suas propriedades físico-químicas e idealmente conjugar duas atividades farmacológicas complementares.

Foram explorados com sucesso métodos de mecanoquímica para obter redes poliméricas 1D de coordenação de níquel a piracetama (Figura 6), um nootrópico ${ }^{3}$ [31]. Com o ácido 4-ami- nosalicílico obtiveram-se igualmente redes de coordenação com prata. A combinação de métodos de estado sólido e solução permitiram a caracterização destes compostos, que mostraram ser estáveis até temperaturas superiores a $100^{\circ} \mathrm{C}$ [31]. Este tipo de complexos com PFAs pode representar uma nova forma para a libertação controlada de fármacos ao nível bioló- 
gico, dada a diferença da estabilidade, solubilidade e biodisponibilidade do fármaco livre relativamente ao fármaco coordenado.

SíNTESE VERDE E EFICIENTE DE METALOFÁRMACOS E ELUCIDAÇÃO ESTRUTURAL PARA COMPREENSÃO DA ATIVIDADE FARMACOLÓGICA

O Pepto-Bismol® é um fármaco usado para problemas digestivos, base-

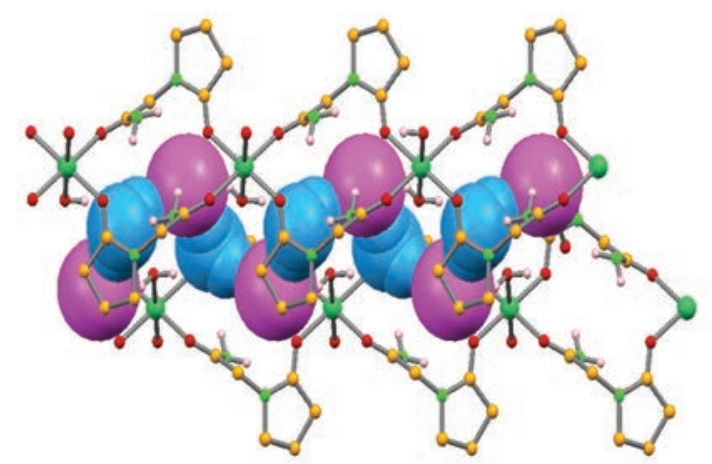

Figura 6 - Arranjo supramolecular do complexo piracetama:Ni, mostrando a rede 1D e a sua interação com a água (azul) e os cloretos (rosa). Apenas estão representados os átomos de hidrogénio envolvidos em pontes de hidrogénio, para uma melhor clareza

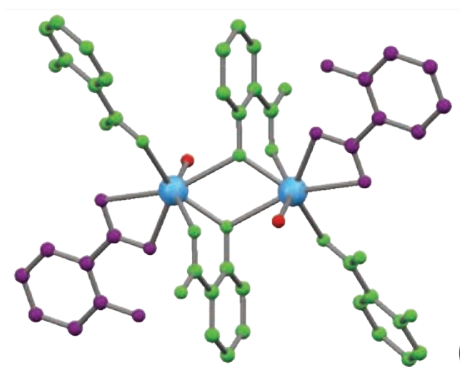

(a)

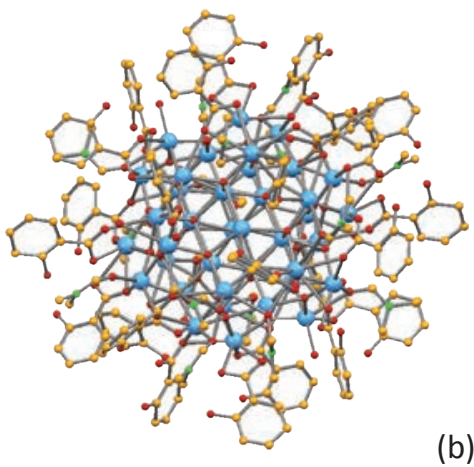

(b) através de moagem assistida por solvente e iões [32]. Os reagentes foram moídos com quantidades catalíticas de solvente e sais de nitrato, os quais não se misturam com o produto final, como provado por RMN de estado sólido, sendo fáceis de separar. Abre-se assim caminho para a produção de fármacos de uma forma mais eficiente a nível energético e menos poluente.

Embora este composto seja usado há mais de um século, a sua estrutura era ainda desconhecida, o que limitava a compreensão da sua atividade farmacológica. Neste estudo foi obtida a primeira estrutura cristalina de salicilato de bismuto sem ligandos auxiliares, bem como de um novo agregado com DMF (Figura 7) [32].

\section{CONCLUSÕES GERAIS}

Foram sintetizados vários polimorfos e formas multicomponentes de PFA, tendo-se conseguido estabelecer correlações entre estrutura e propriedades físico-químicas, sendo de realçar os avanços obtidos na otimização do comportamento dos PFA comercializados. De salientar também que muitos destes novos produtos foram obtidos por métodos de síntese altamente eficientes, que requerem menos energia e solvente, sem a formação de produtos secundários indesejados. Com este trabalho foi dado mais um passo para a "síntese verde" de produtos farmacêuticos.

Figura 7 - (a) Fragmento da estrutura de dissalicilato de bismuto; (b) agregado de salicilato de bismuto com DMF $\left[\mathrm{Bi}_{38} \mathrm{O}_{22}(\mathrm{Hsal})_{26}\left(\mathrm{H}_{2} \mathrm{O}\right)_{4}(\mathrm{DMF})_{18}\right]$

Tabela 1 - Sumário de resultados obtidos na síntese de novas formas cristalinas multicomponentes de PFAs

\begin{tabular}{|c|c|c|c|c|c|}
\hline PFA & Gabapentina & $\begin{array}{l}\text { Gabapentina- } \\
\text { lactama }\end{array}$ & $\begin{array}{c}\text { Ácido 4- } \\
\text { aminosalicílico }\end{array}$ & $\begin{array}{c}\text { Erbumina de } \\
\text { perindopril }\end{array}$ & Paracetamol \\
\hline PROBLEMA & $\begin{array}{c}\text { Elevada } \\
\text { solubilidade }\end{array}$ & $\begin{array}{c}\text { Elevada } \\
\text { solubilidade }\end{array}$ & $\begin{array}{l}\text { Biodisponibili- } \\
\text { dade limitada }\end{array}$ & $\begin{array}{l}\text { Instabilidade à } \\
\text { temperatura }\end{array}$ & $\begin{array}{l}\text { Problemas de } \\
\text { compactação }\end{array}$ \\
\hline RESULTADOS & $\begin{array}{c}\text { Novos } \\
\text { polimorfos } \\
\text { Síntese de } \\
\text { prodrogas } \\
\text { Co-cristaise } \\
\text { sais } \\
\text { moleculares } \\
\text { estáveis com } \\
\text { menor } \\
\text { solubilidade } \\
\text { Relações } \\
\text { estrutura- }\end{array}$ & $\begin{array}{l}\text { Novos co- } \\
\text { cristais estáveis } \\
\text { com menor } \\
\text { solubilidade } \\
\text { Desenvolvimen- } \\
\text { to de modelos } \\
\text { matemáticos de } \\
\text { solubilidade } \\
\text { Relaçōes } \\
\text { estrutura- } \\
\text { propriedades }\end{array}$ & $\begin{array}{c}\text { Sais } \\
\text { polimórficos de } \\
\text { amónia } \\
\text { Relaçōes } \\
\text { estrutura- } \\
\text { estabilidade }\end{array}$ & $\begin{array}{c}\text { Primeiras } \\
\text { estruturas } \\
\text { cristalinas do } \\
\text { PFA } \\
\text { Novo hidrato } \\
\text { com perfil de } \\
\text { dissolução e } \\
\text { solubilidade } \\
\text { semelhantes, } \\
\text { mas mais } \\
\text { estável } \\
\text { Protecção } \\
\text { intelectual }\end{array}$ & $\begin{array}{c}\text { Co-cristais } \\
\text { estáveis com } \\
\text { empacotamento } \\
\text { favorável a uma } \\
\text { uma melhor } \\
\text { compactação }\end{array}$ \\
\hline
\end{tabular}




\section{AgradeCimentos}

A autora agradece a orientação da Professora M. Teresa Duarte e o financiamento da Fundação para a Ciência e a Tecnologia (PPCDT/QUI/58791/2004 e SFRH/BD/40474/2007).

\section{NOTAS}

1 Sintão: unidade estrutural que se repete nas estruturas cristalinas e que permite o design racional de arquiteturas supramoleculares através da análise de padrões de interação recorrentes [5, 14].

2 Grafos: baseiam-se na teoria de grafos e classificam os padrões de pontes de hidrogénio em notações simples de representação geral $G_{d}^{a}(r)$, onde $G$ é o designador do padrão ( $G$ = C para cadeias, $R$ para anéis, $D$ para complexos finitos e S para interações intramoleculares), $r$ é o número de átomos simetricamente independentes envolvidos no padrão, $d$ é o número de doadores e a é o número de aceitadores [15-17].

3 Nootrópico: composto que aumenta o desempenho cognitivo no ser humano.

\section{REFERÊNCIAS}

[1] K. Biradha, C.-Y. Su e J. J. Vittal, Crystal Growth \& Design 11 (2011) 875-886.

[2] M. J. Zaworotko, Nature Chemistry 3 (2011) 653

[3] G. R. Desiraju, Journal of Chemical Sciences 122 (2010) 667-675.

[4] G. R. Desiraju, Current Opinion in Solid State \& Materials Science 13 (2009) 35-35.

[5] A. Nangia, Journal of Chemical Sciences 122 (2010) 295-310.

[6] D. J. Good e N. Rodriguez-Hornedo,
Crystal Growth \& Design 9 (2009) 2252-2264.

[7] M. B. Hickey, M. L. Peterson, L. A. Scoppettuolo, S. L. Morrisette, A. Vetter, H. Guzman, J. F. Remenar, Z. Zhang, M. D. Tawa, S. Haley, M. J. Zaworotko e O. Almarsson, European Journal of Pharmaceutics and Biopharmaceutics 67 (2007) 112-119.

[8] L. S. Reddy, S. J. Bethune, J. W. Kampf e N. Rodriguez-Hornedo, Crystal Growth \& Design 9 (2009) 378-385.

[9] L. Jie, L. Zhen e J. Xiaolin, Front. Chem. Eng. China 4 (2010) 37-44.

[10] S. Karki, T. Friscic, L. Fabian, P. R. Laity, G. M. Day e W. Jones, Advanced Materials 21 (2009) 3905.

[11] T. Beyer, G. M. Day e S. L. Price, Journal of the American Chemical Society 123 (2001) 5086-5094.

[12] G. R. Desiraju, Angewandte ChemieInternational Edition 46 (2007) 83428356.

[13] J. M. Lehn, Pure and Applied Chemistry 59 (1978) 871-892.

[14] G. R. Desiraju, Angewandte ChemieInternational Edition 34 (1995) 23112327.

[15] M. C. Etter, Accounts of Chemical Research 23 (1990) 120-126.

[16] M. C. Etter, J. C. Macdonald e J. Bernstein, Acta Crystallographica Section B-Structural Science 46 (1990) 256-262.

[17] G. A. Jeffrey, An Introduction to Hydrogen Bonding, Oxford University Press, Oxford, 1997.

[18] N. Schultheiss e A. Newman, Crystal Growth \& Design 9 (2009) 29502967.

[19] T. Friscic, D. G. Reid, I. Halasz, R. S. Stein, R. E. Dinnebier e M. J. Duer, Angewandte Chemie-International Edition 49 (2010) 712-715.
[20] D. Braga, F. Grepioni, L. Maini, R. Brescello e L. Cotarca, CrystEngComm 10 (2008) 469-471.

[21] S. Karki, T. Friscic, W. Jones e W. D. S. Motherwell, Molecular Pharmaceutics 4 (2007) 347-354.

[22] F. H. Allen, Acta Crystallographica Section B-Structural Science $\mathbf{5 8}$ (2002) 380-388.

[23] D. Braga, F. Grepioni, L. Maini, K. Rubini, M. Polito, R. Brescello, L. Cotarca, M. T. Duarte, V. André e M. Piedade, New Journal of Chemistry 32 (2008) 1788-1795.

[24] V. André, M. Marques, M. da Piedade e M. T. Duarte, Journal of Molecular Structure 973 (2010) 173-179.

[25] V. André, A. Fernandes, P. P. Santos e M. T. Duarte, Crystal Growth \& Design 11 (2011) 2325-2334.

[26] C. Maheshwari, V. André, S. Reddy, L. Roy, M. T. Duarte e N. RodriguezHornedo, CrystEngComm 14 (2012) 4801-4811.

[27] V. André, D. Braga, F. Grepioni e M. T. Duarte, Crystal Growth \& Design 9 (2009) 5108-5116.

[28] V. André, M. T. Duarte, D. Braga e F. Grepioni, Crystal Growth \& Design 12 (2012) 3082-3090.

[29] V. André, L. Cunha-Silva, M. T. Duarte e P. P. Santos, Crystal Growth \& Design, 2011, 11, 3703-3706.

[30] V. André, L. Cunha-Silva, P. P. Santos, J. Empis e M. T. Duarte, patente registada (2010) PT105315.

[31] D. Braga, F. Grepioni, V. André e M. T. Duarte, CrystEngComm 11 (2009) 2618-2621.

[32] V. André, A. Hardeman, I. Halasz, R. S. Stein, G. J. Jackson, D. G. Reid, M. J. Duer, C. Curfs, M. T. Duarte e T. Friscic, Angewandte ChemieInternational Edition 50 (2011) 78587861.

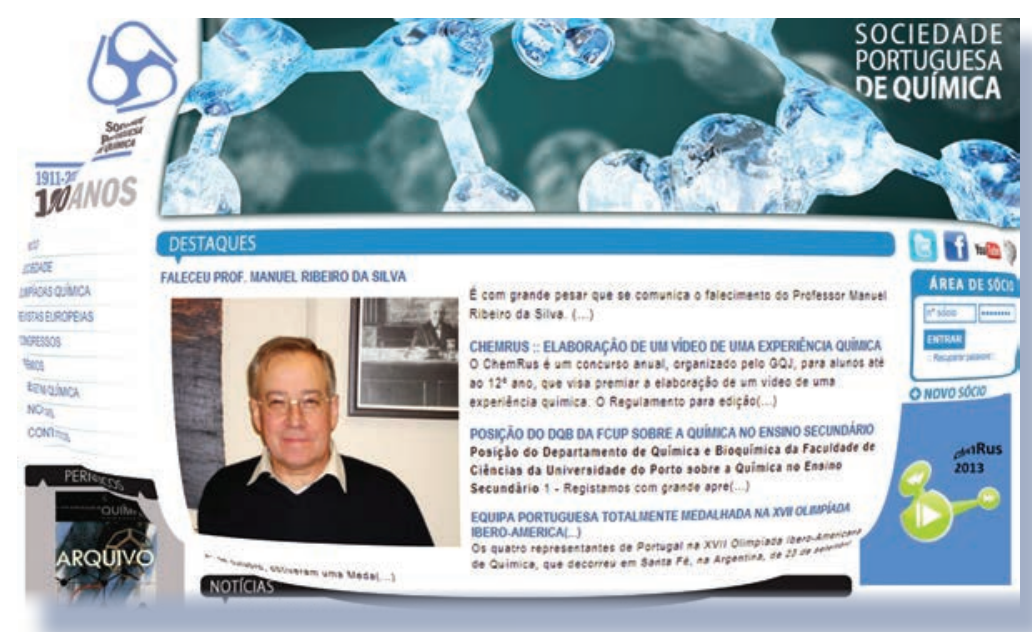




\section{All about Heterogeneous, Homogeneous, and BioCatalysis}

\section{Editorial Board Chairmen:}

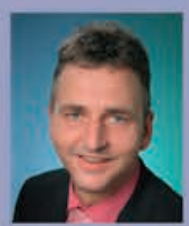

Prof. Uwe Bornscheuer Greifswald University, Germany

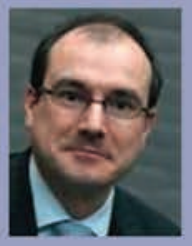

Prof. Bert Weckhuysen Utrecht University, The Netherlands

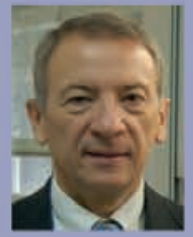

Prof.Luis A. Oro University of Zaragoza, Spain

Focus

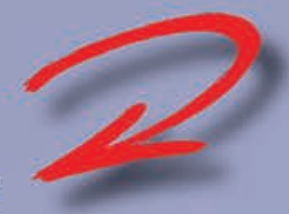

- heterogeneous catalysis

- homogeneous catalysis

- biocatalysis

- protein engineering

- whole cell catalysis

- electrocatalysis

- photocatalysis

- organocatalysis

- metal catalysis

- asymmetric catalysis

- industrial catalysis

- nanocatalysis

- catalytic processes

- surface reactions

- in situ techniques

- spectroscopic methods

- theoretical methods

- catalyst preparation

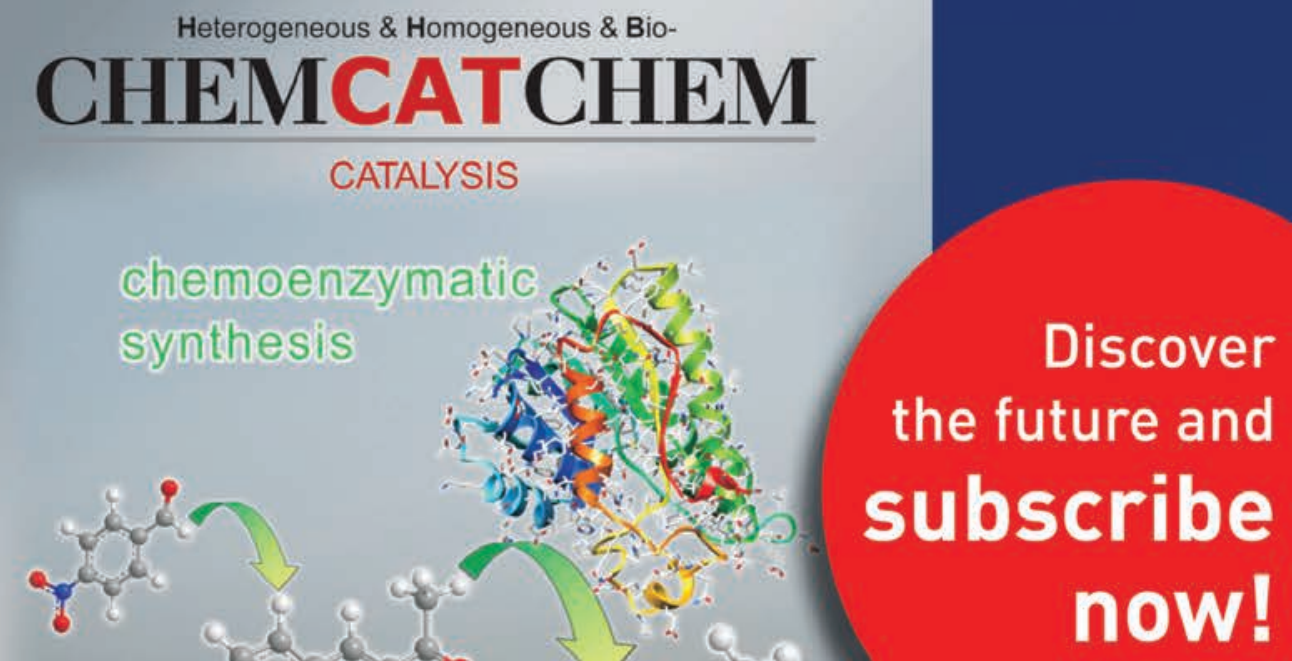

A journal of

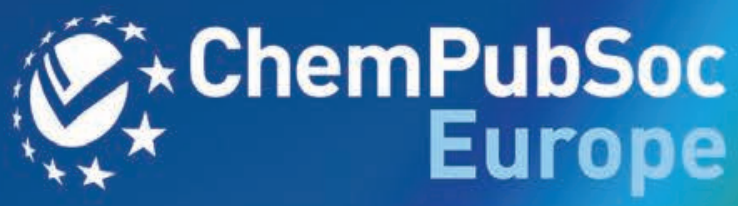

